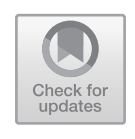

\title{
4
}

\section{Treatment in Barnahus: Implementing Combined Treatment for Children and Parents in Physical Abuse Cases}

\author{
Johanna Thulin and Cecilia Kjellgren
}

\section{Introduction}

Even though corporal punishment has been banned in Sweden since $1979,14 \%$ of children in the ninth grade report being subjected to physical abuse by their parents (Janson et al. 2011). Being exposed to parental violence increases the risk of trauma symptoms such as traumatic stress, depression and behavioural problems (Garbarino et al. 1991; Moffitt 2013). Child victims of physical abuse are also at increased risk of future eating disorders, conduct disorders, alcohol and drug abuse and sexual risk behaviour (Norman et al. 2012).

\footnotetext{
The original version of this chapter was revised: Belated corrections from author have been incorporated. The erratum to this chapter is available at https://doi.org/10.1007/978-3-319-58388-4_17

J. Thulin $(\bowtie) \cdot$ C. Kjellgren

Linnaeus University, Växjö, Sweden

e-mail: johanna.thulin@lnu.se

C. Kjellgren

e-mail: cecilia.kjellgren@lnu.se 
In Sweden, research has shown that children who experience parental physical abuse often continue to live with their parents, even after the abuse has come to the attention of the child welfare service (Lindell and Svedin 2006). Despite this, there has been a lack of specialised intervention for this group of families. The starting point for this chapter is the need for interventions aimed at preventing further violence and increasing the well-being of the child.

The national guidelines for Barnahus in Sweden state that "The goal of the collaboration is to ensure legal rights, good treatment and support, for children who it is suspected are victims of crime, and if necessary immediate crisis and treatment interventions" (The Swedish National Police Agency 2009, 7, author's translation).

Since the decision to introduce Barnahus in Sweden in 2005, the establishment of new Barnahus has been rapid; however, surveys show that a significant number of the Barnahus in Sweden do not adequately provide support, crisis and treatment interventions (Landberg and Svedin 2013).

In this chapter, we describe and discuss an evidence-based intervention that involves both abused children and their parents, in instances where one or both parents are perpetrators of the abuse. The intervention is Combined Parent-Child Cognitive Behavioural Therapy for families at risk of child physical abuse (CPC-CBT), which originates from the USA (Runyon et al. 2004; Runyon and Deblinger 2014) and that currently is being disseminated throughout Sweden in a research project where Linnaeus University and Linköping University collaborate. We argue that the intervention is well suited to the Barnahus context.

Thirty treatment units across Sweden currently offer the treatment, with additional teams being trained. The teams comprise 3-5 colleagues. Half of the trained teams consists of staff from a Barnahus. Some of these teams have social workers from other departments as co-workers in the treatment or cooperate with staff from child and adolescent psychiatric units.

If this treatment was used systematically, a higher percentage of Barnahus in Sweden would meet the criteria for Barnahus in the national guidelines. Through their collaboration with other professionals, Barnahus also has a unique opportunity to offer interventions to both children and their families in cases of suspected parental physical abuse. 
Because the Barnahus staff meets families at a time of crisis, they are also strategically positioned to offer them voluntary forms of treatment.

In the following, we first present the basics of the CPC-CBT model and the Swedish version of the model named Kognitiv integrerad behandling vid barnmisshandel (KIBB). We then present the results from a large-scale dissemination project in Sweden and discuss possible implications for interventions in Barnahus.

\section{Combined Parent-Child Cognitive Behavioural Therapy (CPC-CBT)}

The CPC-CBT intervention was developed in the USA by Runyon and colleagues at CARES Institute (Child Abuse Research Education and Service) in New Jersey (Runyon et al. 2004). The method was evaluated with good results (Runyon et al. 2009; Runyon et al. 2010), and later, the manual was thoroughly presented (Runyon and Deblinger 2014). The method is unique in combining treatment for both children and parents in families where physical abuse has occurred (Runyon et al. 2004). The CPC-CBT is included in the National Registry of Evidencebased Programmes and Practices (NREPP) list of evidence-based practices in the USA. Cecilia Kjellgren, Ph.D., the second author of this chapter, introduced CPC-CBT in Sweden in cooperation with Children's Welfare Foundation Sweden (Stiftelsen Allmänna Barnhuset). ${ }^{1,2}$

CPC-CBT is an intervention that aims to help the whole family, including the violent parent, according to the manual (Children's Welfare Foundation Sweden 2013; Runyon and Deblinger 2014). The child welfare services may refer families to treatment where physical abuse has occurred. Initially, child welfare services assess whether the intervention is appropriate in terms of both the needs of the family and the safety of the child. The aim of the treatment is to end all forms of physical abuse, including more severe child abuse. The child welfare service is responsible for the child's safety throughout the treatment and keeps in contact with the family and the therapists. Before treatment starts, the parents have to sign a non-violence contract. The therapist also informs parents about their professional obligation to the 
mandatory reporting of possible new abuse events to the child welfare services. Participation in treatment is voluntary.

The child receives treatment either individually or within a group of children, and the parents meet a therapist individually or join a group of parents for the sessions; consequently, the child meets one therapist and the parents meet another therapist simultaneously. Every treatment session ends with an integrated period where the family join together with one of the therapists, where parents can rehearse and practice new parenting strategies. Not all parents admit that they have been abusive, at least not in the beginning of the treatment. Initially, the child's story will be the starting point, sometimes a story that has been told by the child to the police. The parents usually admit having violent behaviour to some extent, such as being too harsh or grabbing the child too hard. Since the child holds the right to their own version and experience, the therapist will work with that story, both with the child and with the parents. Initially, the parents have to give the child permission to talk about the abuse. Further, they have to agree that there should be no more secrets, and this will be repeated several times during treatment to encourage the child to openly describe the details of their experiences and related thoughts and feelings.

CPC-CBT is an outpatient treatment intervention. Families attend approximately 16 sessions over a 16- to 20-week period, where therapists meet the family during a $2 \mathrm{~h}$ session weekly. Each week, specific themes are addressed according to the structured treatment manual (Runyon and Deblinger 2014). CPC-CBT has four phases: (1) engagement and psychoeducation, (2) effective coping skills, (3) family safety planning and continuation of skill building and (4) abuse clarification. Parenting skills are addressed across all phases.

\section{Child Treatment}

During the initial phase, engagement and psychoeducation, children learn about violence and abuse, and possible consequences in order to understand their own reactions and to acknowledge them. This is the beginning of a gradual process of exposing the child to abuse-related 
material to increase the child's comfort level in dealing with, and directly discussing, personal experiences of abuse.

During the effective coping skills phase, children learn to identify, regulate and appropriately express their emotions, and learn productive coping strategies for dealing with stress and anxiety in order to reduce their anxiety and to prepare them to manage to share the details of their abusive experiences. An essential part of the treatment is to help the child to understand and express their feelings. Some children lack the ability to regulate their feelings. The treatment is based on cognitive behavioural therapy, and the therapist tries to clear the connection between the child's thoughts, feelings and behaviour. Many children initially blame themselves for the abuse and may explain that it all happened because of their own behaviour. Such beliefs will be clarified later in treatment, together with the parents, and the parents can then take responsibility for acting wrongly. Considering the child's age and maturity, activities such as games, role-play and tools can be used as part of the therapy.

While safety is integral to every phase of CPC-CBT, the family safety planning phase focuses specifically on having family members develop and implement a safety plan that involves using the skills learned to date, in order to enhance the safety of all family members. The treatment starts with giving the child space and time to describe the specific occasion that led to the police report or the report to the child welfare service. This episode can be very frightening, and children may need to repeatedly talk it over, to explain what they have experienced and how their parents behaved. Children need to be reassured that they did not do anything that made them deserve to be hit or abused.

The final phase of therapy, the abuse clarification phase, involves the child developing a trauma narrative. This occurs after there is evidence in parent and child reports that the physical abuse has stopped and that positive parent-child interactions have increased. The therapist encourages the child to share a narrative about their specific experiences of abuse. The child will describe the situation, how they thought and felt. In this process, some children draw pictures or cartoons; other will play in sand or use dolls or character cards. The child and therapist will try to write the narrative down together and read it aloud to 
repeatedly expose the child to the anxiety-provoking memory in order to decrease anxiety and trauma symptoms. The therapist also assists the child with processing dysfunctional and self-blaming thoughts that may surface/occur during joint sessions with the parents. The child is asked whether they have questions concerning the abuse to ask their parents and whether they want the parents' therapist to forward the questions. When the child is ready, the story will be shared with the parents, and they will respond to it (see Section "Parent Treatment").

\section{Parent Treatment}

During the engagement and psychoeducation phase, parents discuss and process their personal experiences of abuse and violence, which can contribute to an increase in empathy for their children's experience of their relationship and current parenting style. They examine how children can be affected by growing up in a violent environment. Parents receive psychoeducation and learn more about the consequences of child abuse and maltreatment, about child development and the needs of a child.

Teaching parents alternative non-violent parenting strategies is a critical part of the treatment and is integrated into all phases. Parents learn active listening to strengthen communication with the child and to prepare them for the abuse clarification phase. The foundation of positive parenting skills is to encourage parents to express more appreciation, to affirm and praise their child. Parents are taught how to reinforce some behaviours and to reduce others.

During the effective coping skills phase, parents learn a variety of strategies for dealing with and expressing anger. They are also taught how to understand and express their own feelings in a different way. Many parents also need help to regulate their emotions, not least their anger. Anger management is a central part of the treatment. In the same way as the child, the parents will learn how thoughts, feelings and behaviours interact. They will practice how to communicate with their children, including how to listen.

In the final phase, abuse clarification, parents prepare an abuse clarification letter for their child which demonstrates that they take 
responsibility for their abusive behaviour and alleviate the child of blame. They also outline their commitment to parent their child in a more positive way. The child's trauma narrative is shared with the parent, and the parent can thus respond directly to any misconceptions, fears or concerns the child has about the abuse. This can be a very emotional moment, and the parent is prepared by first reading the child's narrative together with the therapist. When both parent and child are prepared, the child will share the narrative with the parent. The parent will also respond by writing a letter of clarification, where the parents will try to explain why they attended treatment, take full responsibility for the abuse situation(s) and explain how they feel about the child talking about the abuse. The parents will also try to describe what they have learned and how they hope to act differently from now on.

\section{Joint Sessions}

During joint sessions, children and parents will together create a security plan in order to avoid the escalation of future stressful situations and to prevent the risk of further abuse. The parents will also have opportunities to practice new parenting strategies. Both parents and children practice different skills, such as affirming and praising each other.

\section{Implementation and Adaptions to the Swedish Context}

Four teams participated in a pilot project during the initial CPCCBT training in Sweden. The professionals had high expectations, but expressed doubts about the applicability of the model in the Swedish context due to cultural differences. The definition of physical abuse is not the same in Sweden as in the USA, where there is zero tolerance for parental physical violence in Sweden. This may indicate that victims of physical abuse are more severely abused and more burdened when being referred to treatment in the USA, compared to Sweden. 
When the interventions were introduced in a Swedish context, minor adaptations were made in agreement with the programme developer (e.g. modification of language and exclusion of parenting strategies that are less relevant in the Swedish context) while maintaining the overall structure and constructs of the original model.

Initially, it was not known whether the method would integrate well with the work at the Barnahus. Three of the four teams in the pilot project were teams of Barnahus staff, and they reported valuable positive experiences while implementing CPC-CBT. The experience was positive for those teams who could present the treatment as an option at an early stage, provided they were in close cooperation with the child welfare caseworker. Later practice further confirmed these initial experiences.

A pilot study was conducted in 2010-2011 (Kjellgren et al. 2013), with a pre- and post-treatment design. The study had several positive results for children and parents. Children showed significantly reduced trauma symptoms and symptoms of depression at post-treatment. They also reported that parents had significantly improved in positive parenting and reduced corporal punishment. Significantly, fewer symptoms of depression were reported by parents at follow-up post-treatment as well as less use of violent parenting strategies and less inconsistent parenting behaviours (Kjellgren et al. 2013). Previous studies in the USA showed that similar effects of the treatment (more positive parenting, less physical abuse and increased emotional well-being for the children) persisted at follow-up, 3 months later (Runyon et al. 2010). Following such positive experiences of the pilot project, the intervention was further implemented by training a number of additional therapists across Sweden, starting in 2013. When the first invitation for training was announced, staff at the Barnahus were given priority. So far about one hundred therapists have been trained in the method in Sweden. A large-scale Swedish dissemination study to evaluate the outcomes associated with CPC-CBT was also planned. This study consists of three data collection periods, at pre-treatment before treatment has started, at post-treatment approximately 4 months later when treatment is completed and at a 6-month follow-up (see Fig. 4.1). The study is ongoing, and more than 50 children have participated in the first data collection period. The aim is to assess 50 children and their parents overall three data collection periods. We also intend to collect data from control families to 


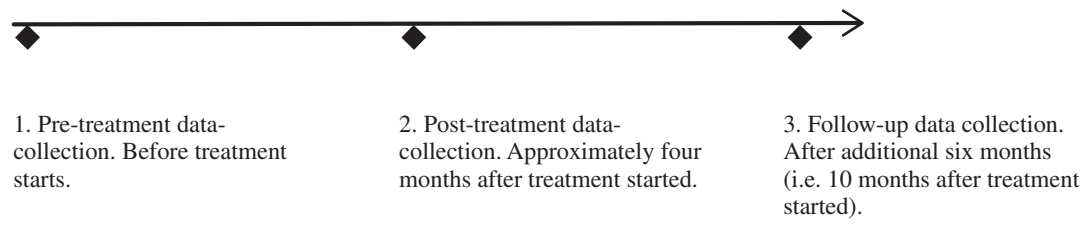

Fig. 4.1 Research design

make outcome comparisons possible. Families who have been assessed and offered CPC-CBT treatment by one of the teams previously mentioned were all informed about the study and asked whether they (parents and children) wanted to participate in the ongoing research.

\section{Results}

The results in this chapter have previously been published within a Swedish report (Thulin et al. 2015). This chapter presents the data of a subsample of 34 children and their parents $(N=45)$, from a total of 28 families, who have completed pre- and post-data collections. Slightly, more boys (58\%) than girls (42\%) participated in the study, and their mean age was 9.5 years $(\mathrm{SD}=2.2)$. In the parent group, $50 \%$ were mothers and $46 \%$ fathers, and $4 \%$ were step-fathers. The parents average age was 39 years $(\mathrm{SD}=6.7)$. Both children and parents completed self-assessment scales. The results were statistically analysed. Mean values were compared (the data from preversus post-treatment) using paired $t$ tests in order to measure change at the individual level. Effect size was calculated and is presented using Cohen's $\mathrm{d}$. The cut-off points for Cohen's $\mathrm{d}$ used in the analyses are $\geq 0.80$ (indicating large effect), $\geq 0.50$ (moderate effect) and $\geq 0.20$ small effect).

\section{Parenting Measurements}

\section{Trauma Symptoms}

Parents were asked to estimate the child's trauma symptoms on the parent report scale Trauma Symptom Checklist for Young Children (TSCYC, Briere et al. 2001). The scale contains 90 items, and these 
Table 4.1 Parents reporting differences in their children's well-being before and after treatment, $N=36$

\begin{tabular}{llllll}
\hline \multicolumn{7}{l}{ Before treatment } & After treatment & & \\
\hline Variable & $M(\mathrm{SD})$ & $M(\mathrm{SD})$ & $t$ & $p$ & $d$ \\
\hline Anxiety & $12.89(3.55)$ & $11.31(2.55)$ & 3.75 & 0.001 & 0.52 \\
Depression & $13.15(3.62)$ & $11.24(1.97)$ & 3.56 & 0.001 & 0.71 \\
Anger & $14.37(4.48)$ & $12.20(3.64)$ & 3.67 & 0.001 & 0.54 \\
PTS-intrusion & $11.50(2.83)$ & $10.18(1.66)$ & 3.16 & 0.003 & 0.57 \\
PTS-avoidance & $11.12(3.17)$ & $10.18(1.99)$ & 2.06 & 0.047 & 0.35 \\
PTS-arousal & $13.56(4.37)$ & $12.38(3.06)$ & 2.39 & 0.023 & 0.32 \\
Dissociation & $12.94(3.40)$ & $11.29(2.98)$ & 3.27 & 0.002 & 0.50 \\
Total trauma & $120.46(27.99)$ & $106.43(19.41)$ & 3.65 & 0.001 & 0.61 \\
\multicolumn{1}{l}{ symptoms } & & & & & \\
\hline
\end{tabular}

were translated into Swedish and validated in a Swedish study (Nilsson et al. 2012). TSCYC contains eight subscales: anxiety, depression, anger, post-traumatic stress disorder (divided into three subscales), dissociation and sexual concerns. Parents rate whether the child shows symptoms using a four-point scale where $1=$ not at all and $4=$ very often. Due to the young age of the children participating in this study, the sexual concern subscale, which measures sexual thoughts and feelings, was not considered relevant.

The results showed that parents reported that the symptoms of the children had significantly decreased on all variables (see Table 4.1), from pre- to 4 months post-treatment. Parents reported that their children showed significantly less extrovert behaviour such as anger, as well as decreased introvert behavioural problems, such as anxiety, depression, post-traumatic stress symptoms and dissociation after treatment.

\section{Parenting Strategies}

Parenting strategies were measured by the Alabama Parenting Questionnaire (APQ, Frick 1991). The questionnaire measures five parenting strategies. The results for three subscales, positive parenting, inconsistent discipline and corporal punishment are presented in this chapter (see Table 4.2). Positive parenting includes praising and rewarding children, and the extent to which the parents show affection for 
Table 4.2 Mean differences in parenting strategies after treatment (APQ-P), $N=41$

\begin{tabular}{|c|c|c|c|c|c|}
\hline & Before treatment & After treatment & & & \\
\hline Variable & $M(\mathrm{SD})$ & $M(\mathrm{SD})$ & $t$ & $p$ & $d$ \\
\hline Positive parenting & $24.37(3.27)$ & $24.20(3.93)$ & 0.42 & 0.680 & 0.05 \\
\hline $\begin{array}{l}\text { Inconsistent } \\
\text { discipline }\end{array}$ & $14.11(3.45)$ & $12.95(2.94)$ & 2.18 & 0.036 & 0.38 \\
\hline $\begin{array}{l}\text { Corporal } \\
\text { punishment }\end{array}$ & $3.56(1.27)$ & $3.05(0.32)$ & 2.64 & 0.012 & 0.63 \\
\hline
\end{tabular}

the child. Inconsistent discipline regards to what extent their parent's behaviour is predictable to the child. The corporal punishment subscale includes items describing three kinds of punishing behaviour (spanking, slapping or hitting with an object).

The results reveal that parents became significantly more consistent and therefore more predictable for the children after treatment. This in turn can be interpreted as leading to a sense of security, when the child more easily understood the rules and how their parents might react. The results also revealed that parents significantly reduced their use of corporal punishment (the summarised value 3 indicates no use of physical punishment); however, parent responses did not suggest that they had been more positive in their parenting.

\section{Parents' Psychological Well-Being}

Parent's well-being changed after receiving treatment. The mean depression scores were significantly reduced, from $M=12.37(\mathrm{SD}=13.28)$ to $M=6.14(\mathrm{SD}=7.63)(t=3.69, p=0.001)$. The questionnaire used, Beck Depression Inventory (BDI, Beck, Steer and Brown 1996), is a well-established self-assessment scale for measuring symptoms of depression in adults. The total scores of symptoms are categorised into four levels: minimal, mild, moderate and severe depression (Beck et al. 1996). The share of parents who reported mild, moderate or severe depression was reduced after treatment. The treatment method does not explicitly aim to reduce depression, but the results suggest that treatment components affect depressive feelings. Previous feelings among 
parents, such as guilt about parental failure, are probably reduced by treatment when parents achieved alternative strategies such as improved consistent parenting. This could affect the reduction of symptoms.

\section{Children and Trauma}

Being subjected to abuse by a parent is serious and increases the risk of trauma symptoms, depression and behavioural problems in children (Garbarino et al. 1991; Moffitt 2013). Previous research has also shown that children who have been exposed to trauma are more likely to be exposed again; re-victimised (Gilbert et al. 2009) and also to be exposed to other types of trauma; and poly-victimised (Clarkson Freeman 2014). Children in this study completed the Linköping Youth Life Experiences Scale (LYLES) and were asked whether they had experienced various events. The scale is divided into three types of events: non-interpersonal events (nIPE), interpersonal events (IPE) and adverse childhood circumstances (ACC) (Nilsson et al. 2010). Examples of items concerning non-interpersonal events are whether the child has experienced a burglary or seen a fire. Interpersonal items include, for example, whether the child has been exposed to violence or sexual abuse. Items in the subscale of adverse childhood circumstances include whether the child has been subjected to bullying or has had a prolonged illness.

Our sample of children who have been physically abused experienced a mean of 13.1 (SD 6.1) potential traumatic events, with a range between 3 and 22. Some of the most prevalent forms of potential traumatic non-interpersonal events were the experience of a family member in hospital (85\%) and experience of the death of a close person (72\%). The most frequent interpersonal events were being hit or injured by an adult in the family $(82 \%)$, being hit or injured by another adult $(65 \%)$ and being the witness when another person was hit or injured (42\%). The most frequent adverse childhood experiences were having experienced parents separation or divorce (44\%), having been bullied (41\%) and having been emotionally abused (33\%).

Being exposed to such a high number of potentially traumatic events is categorised as being poly-victimised (e.g. Turner et al. 2010). 
Children's trauma symptoms are also likely to increase according to the number of events (Turner et al. 2010). The result from our study confirms earlier studies, which revealed that physically abused children are a vulnerable group where the likelihood is strong that they have been exposed to other types of trauma in addition to the abuse.

\section{Trauma Symptoms}

The children completed the self-assessment scale Trauma Symptom Checklist for Children (TSCC, Briere et al. 2001). The results (see Table 4.3) revealed that the participating children significantly reduced their trauma symptoms after treatment for all tested variables: anxiety, feelings of depression, anger, post-traumatic stress and dissociation.

The results confirm those of previous research that the CPC-CBT method supports child victims of physical abuse.

\section{Children's Experience of Parenting Strategies}

Children were asked how they perceived the parenting strategies used by their parents before and after treatment (see Table 4.4).

Children, as well as parents, responded that the use of corporal punishment was significantly reduced after treatment (the summarised value 3 indicates no use of physical punishment). Although both children and parents reported that the violence had decreased significantly,

Table 4.3 Children's trauma symptoms before and after treatment (TSCC), $N=25$

\begin{tabular}{llllll}
\hline & $\begin{array}{l}\text { Before } \\
\text { treatment }\end{array}$ & $\begin{array}{l}\text { After } \\
\text { treatment }\end{array}$ & & & \\
\hline & $M(\mathrm{SD})$ & $M(\mathrm{SD})$ & $t$ & $p$ & $d$ \\
\hline Anxiety & $5.84(3.14)$ & $4.0(2.38)$ & 2.85 & 0.009 & 0.64 \\
Depression & $4.72(3.49)$ & $2.68(2.21)$ & 2.81 & 0.010 & 0.69 \\
Anger & $5.88(3.86)$ & $3.72(2.42)$ & 3.02 & 0.006 & 0.69 \\
PTSD & $7.32(4.58)$ & $5.44(2.89)$ & 2.22 & 0.036 & 0.50 \\
Dissociation & $5.72(3.18)$ & $4.08(1.96)$ & 2.46 & 0.022 & 0.62 \\
Total trauma symptoms & $29.48(13.82)$ & $19.92(8.97)$ & 3.70 & 0.001 & 0.84 \\
\hline
\end{tabular}


Table 4.4 Children's reports of parenting strategies, $N=33$

\begin{tabular}{|c|c|c|c|c|c|}
\hline & Before treatment & After treatmen & & & \\
\hline Variable & $M(\mathrm{SD})$ & $M(\mathrm{SD})$ & $t$ & $p$ & $d$ \\
\hline Positive parenting & $22.28(5.00)$ & $23.69(4.00)$ & 1.79 & 0.084 & 0.31 \\
\hline $\begin{array}{l}\text { Inconsistent } \\
\text { discipline }\end{array}$ & $14.28(3.73)$ & $12.86(3.30)$ & 1.74 & 0.093 & 0.40 \\
\hline $\begin{array}{l}\text { Corporal } \\
\text { punishment }\end{array}$ & 4.25 (1.68) & $3.09(0.39)$ & 3.68 & 0.001 & 1.1 \\
\hline
\end{tabular}

their responses differed. Children estimated that corporal punishment was more common at pre-treatment than did the parents. This difference highlighted the need to also talk to children when various conditions in a family are investigated. Previous studies have shown that parents tend to under-report children's experiences of abuse (Kjellgren et al. 2013; Svensson 2013; Litrownik et al. 2003).

\section{Discussion}

In this chapter, we have described how the CPC-CBT intervention aimed to reduce the risk of re-victimisation and to increase the wellbeing of children who have been exposed to parental physical violence. We have also described how the method has been implemented in Sweden. Some noteworthy results can be highlighted from the ongoing Swedish research.

We identified significantly reduced trauma symptoms in children at post-treatment, reported by children as well as parents. The abused children in the study reported high levels of various potentially traumatic experiences beyond being the victims of physical violence. The findings underline the need to organise relevant support and intervention for children so as to reduce traumatic stress. The treatment components in CPC-CBT seem to meet those needs and to support children by increasing their well-being. Parents reported significantly more consistency in their child-rearing and less use of corporal punishment after treatment. One of the aims of the treatment is to support parents in developing alternative, non-violent parenting skills and improved 
communication with their child. When parents achieve improved parenting skills and experience positive changes within the family, this may affect their well-being and probably affect the reduction of depressive symptoms in parents, as identified in the study.

The data from the previous Swedish pilot study (Kjellgren et al. 2013) reflected comparable pre- and post-treatment results as found in this study. When comparing Swedish data with US data (Runyon et al. 2009), the results of children as well as parents are very much the same regarding how children and parents report positive changes in parenting strategies and decreasing levels of depression and trauma symptoms in children. This could indicate the similarities of families where child physical abuse has occurred, despite several (other) differences when comparing the USA and Sweden.

The aim of the research project presented here was to explore the outcome of CPC-CBT compared to other interventions, by including a comparison group of children and parents receiving treatment as usual from child welfare services. Several attempts were made in different municipalities to recruit families to a control group. Despite the willingness of colleagues to assist, comparison data have not yet been collected due to difficulties in recruiting families. We could only speculate about the reasons. One reason could be that the staff at the Barnahus or child welfare services that do not offer specialised interventions might find it difficult to ask families to participate in research when the family is not offered an intervention designed for parental abusive behaviour.

Some of the treatment units reported serving a large number of immigrant families, using CPC-CBT. In one-third of the 28 families participating in this study, one or both parents had an ethnic origin other than Swedish. The post-treatment outcomes for these families are equally positive, but as a future goal when the treatment method serves families from other cultural contexts, the treatment programme as well as the therapists needs to be sensitive to religious beliefs and values that are central for the family, as concluded by a number of studies (SantaSosa and Runyon 2015; Partridge and Walker 2015; Damra et al. 2014). This could lead to an improvement in the treatment by using metaphors and beliefs that are more relevant to family values, beliefs and traditions and thus, more helpful for families. It is also necessary to 
approach families with respect by offering support to children and families from different cultural contexts in a sensitive way. It is important to identify the strengths associated with their values, beliefs and traditions, and to integrate these constructs into treatment to enhance family engagement throughout the treatment process.

Barnahus has an important role in, and potential to, identify and support families in need of further interventions. Since both child welfare services and child and adolescent psychiatric units collaborate within the Barnahus, there is a strong foundation for organising the support of families. Earlier evaluations have identified the need for further interventions (Åström and Rejmer 2008), but there has also been discussion about the role of the Barnahus in giving further support and long-term treatment (e.g. Stefansen et al. 2012; Chap. 16 in this book).

According to this ongoing research study, Barnahus is a suitable agency for providing treatment to families when physical abuse had occurred. The Barnahus staff meets families in crisis and could thus present the treatment as an option at an early stage. Barnahus staff are well experienced in assisting families where physical violence has been present and do not fear talking about the abuse. When meeting new families where physical abuse has been identified, the staff at Barnahus can also talk about the potential for change in a trustworthy way, because they have experienced such change in other families after treatment.

\section{Conclusion}

There have been a number of positive experiences in implementing CPC-CBT in Sweden for physically abused children and their families, which support the further dissemination of the intervention across the country. The experiences of the 10 teams from Swedish Barnahus participating in the project so far is that the method works very well in the Barnahus setting, as a possible early intervention when child physical abuse has been disclosed and the child welfare caseworkers have concluded that CPC-CBT is the right intervention with regard to child protection needs. The ongoing study confirms the previous research findings of traumatic stress associated with child physical abuse. 
Given that child physical abuse has both short- and long-term consequences for the individual child, it is important that Barnahus, as well as other agencies, have the tools and ability to pay attention to abused children and provide interventions that meet the needs of families in crisis, as well as prevent further violence. The positive results of the study need to be further investigated in line with the research plan (Fig. 4.1). It is important to evaluate whether parents maintain the good, non-violent parenting strategies reported at post-treatment ( 4 months) and whether the increased well-being of the children is still present at the 6-month follow-up.

\section{Notes}

1. The Children's Welfare Foundation holds the Swedish rights to use the treatment manual that is provided for those who have participated in the CPC-CBT therapist training. There is no financial gain in providing the manual or disseminating the programme.

2. The Public Health Agency of Sweden (Folkhälsomyndigheten) supported the implementation of the intervention across the country.

\section{References}

Åström, Karsten and Annika Rejmer. 2008. Det blir nog bättre för barnen...

Slutrapport i utvärderingen av nationell försöksverksamhet med barnahus 2006-2007. Lund: Lund University, Research Report in Sociology of Law 2008:7.

Beck, Aaron T., Robert A. Steer and Gregory K. Brown. 1996. Beck

Depression Inventory, 2nd ed. Manual, Swedish version. Sandviken: Psykologiförlaget AB.

Briere, John, Kerri Johnson, Angela Bissada, Linda Damon, Julie Crouch, Eliana Gil, Rochelle Hanson, and Vickie Ernest. 2001. The Trauma Symptom Checklist for Young Children (TSCYC): Reliability and Association with Abuse Exposure in a Multi-Site Study. Child Abuse and Neglect 25 (8): 1001-1014. 
Children's Welfare Foundation Sweden. 2013. KIBB - Kognitiv Integrerad behandling vid Barnmisshandel. Treatment manual. Stockholm: Children's Welfare Foundation Sweden.

Clarkson Freeman, Pamela A. 2014. Prevalence and Relationship Between Adverse Childhood Experiences and Child Behavior Among Young Children. Infant Mental Health Journal 35 (6): 544-554.

Damra, Jalal Kayed M., Yahia H. Nassar, and Thaer Mohammd F. Ghabri. 2014. Trauma-Focused Cognitive Behavioral Therapy: Cultural Adaptations for Application in Jordanian Culture. Counselling Psychology Quarterly 27 (3): 308-323.

Frick, Paul J. 1991. The Alabama Parenting Questionnaire. Unpublished Rating Scale, University of Alabama.

Garbarino, James, Kathleen Kostelny, and Nancy Dubrow. 1991. What Children Can Tell us About Living in Danger. American Psychologist 46 (4): 376-383.

Gilbert, Ruth, Cathy Spatz Widom, Kevin Browne, David Fergusson, and Elspeth Webband Staffan Janson. 2009. Burden and Consequences of Child Maltreatment in High Income Countries. Lancet 373 (9657): 68-81. Janson, Staffan, Carolina Jernbro and Bodil Långberg. 2011. Kroppslig bestraffning och annan kränkning av barn i Sverige. En nationell kartläggning 2011. Stockholm: Stiftelsen Allmänna Barnhuset.

Kjellgren, Cecilia, Carl Göran Svedin, and Doris Nilsson. 2013. Child Physical Abuse-Experiences of Combined Treatment for Children and their Parents: A Pilot Study. Child Carein Practice 19 (3): 275-290.

Landberg, Åsa and Carl Göran Svedin. 2013. Inuti ett barnahus. En kvalitetsgranskning av 23 svenska verksamheter. Stockholm: Save the Children Sweden.

Lindell, Charlottaand, and Carl Göran Svedin. 2006. Social Services Provided for Physically Abused Children: A Four Year Follow-Up Study in Sweden. Child and Adolescent Social Work Journal 5-6: 597-616.

Litrownik, Alan J., Rae Newton, Wanda M. Hunter, Diana English, and Mark D. Everson. 2003. Exposure to Family Violence in Young at-risk Children: A Longitudinal Look at the Effects of Victimisation and Witnessed Physical and Psychological Aggression. Journal of Family Violence 18 (1): 59-73.

Moffitt, Terrie E. 2013. Childhood Exposure to Violence and Lifelong Health: Clinical Intervention Science and Stress-Biology Research Join Forces. Development and Psychopathology 25: 1619-1634.

Nilsson, Doris, Per E. Gustafsson, and Carl Göran Svedin. 2012. The Psychometric Properties of the Trauma Symptom Checklist for Young Children in a Sample of Swedish Children. European Journal of Psychotraumatology 3: 1-12. 
Nilsson, Doris, Per E. Gustafsson, Jessica Larsson, and Carl Göran Svedin. 2010. Evaluation of the Linköping Youth Life Experience Scale. Journal of Nervous and Mental Disease 198 (10): 768-774.

Norman, Rosana E., Munkhtsetseg Byambaa, Rumna De, Alexander Butchart, James Scott, and Theo Vos. 2012. The Long-Term Health Consequences of Child Physical Abuse, Emotional Abuse, and Neglect: A Systematic Review and Meta-Analysis. PLoS Medicine 9 (11): 1-31.

Partridge, Kathrine J., and Donald F. Walker. 2015. Addressing Spiritual Struggles Using Spiritually Oriented Trauma-Focused Cognitive Behavioural Therapy: An International Case Study. Journal of Psychology \& Christianity 34 (1): 84-88.

Runyon, Melissa K., and Esther Deblinger. 2014. Combined Parent-Child Cognitive Behavioral Therapy. An Approach to Empower Families At-Risk for Child Physical Abuse. Therapist Guide. Oxford: Oxford University Press.

Runyon, Melissa K., Esther Deblinger, and Christine M. Schroeder. 2009. Pilot Evaluation of Outcomes of Combined Parent-Child CognitiveBehavioral Group Therapy for Families at Risk for Child Physical Abuse. Cognitive and Behavioral Practice 16: 101-118.

Runyon, Melissa K., Esther Deblinger, and Robert A. Steer. 2010. Group Cognitive Behavioral Treatment for Parents and Children at-risk for Physical Abuse: An Initial Study. Child \& Family Behavior Therapy 32 (3): 196-218.

Runyon, Melissa, Esther Deblinger, Erika Ryan, and Reena Thakkar-Kolar. 2004. An Overview of Child Physical Abuse: Developing an Integrated Parent-Child Cognitive-Behavioral Treatment Approach. Trauma, Violence \& Abuse 5: 65-85.

Santa-Sosa, Eileen, and Melissa Runyon. 2015. Addressing Ethnocultural Factors in Treatment for Child Physical Abuse. Journal of Child and Family Studies 24 (6): 1660-1671.

Stefansen, Kari, Tonje Gundersen and Elisiv Bakketeig. 2012. Barnehusevalueringen 2012, delrapport 2. En undersøkelse blant barn og pårørende, samarbeidspartnere, ledere og ansatte. Oslo: NOVA, rapport nr. 9. Svensson, Birgitta. 2013. Barn som riskerar att fara illa i sin hemmiljö. Utmaningar i ett förebyggande perspektiv. Dissertation, Karlstad Universitet, Karstad.

Swedish National Police Agency. 2009. Delredovisning av regeringsuppdrag avseende gemensamma nationella riktlinjer kring barn som misstänks vara utsatta för brott och kriterier för landets barnahus. Stockholm: The Swedish National Police Agency. 
Thulin, Johanna, Cecilia Kjellgren, and Doris Nilsson. 2015. Forskningsstudien. In Slutrapport KIBB projektet. Kognitiv Integrerad Behandling vid Barnmisshandel 2013-2015, ed. Carl Göran Svedin, Doris Nilsson, Cecilia Kjellgren, Johanna Thulin, Lotta Lindgren, and Ylva Söderlind Göthner. Stockholm: Stiftelsen Allmänna Barnhuset.

Turner, Heather A., David Finkelhor, and Richard Ormrod. 2010. PolyVictimization in a National Sample of Children and Youth. American Journal of Preventive Medicine 38 (3): 323-330.

Open Access This chapter is licensed under the terms of the Creative Commons Attribution 4.0 International License (http://creativecommons. org/licenses/by/4.0/), which permits use, sharing, adaptation, distribution and reproduction in any medium or format, as long as you give appropriate credit to the original author(s) and the source, provide a link to the Creative Commons license and indicate if changes were made.

The images or other third party material in this chapter are included in the chapter's Creative Commons license, unless indicated otherwise in a credit line to the material. If material is not included in the chapter's Creative Commons license and your intended use is not permitted by statutory regulation or exceeds the permitted use, you will need to obtain permission directly from the copyright holder.

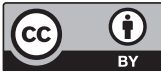

